\title{
Rhetoric in standard setting: the case of the going-concern audit
}

\author{
The Authors
}

\author{
Walter Masocha, Department of Accounting, Finance and Law, University of \\ Stirling, Stirling, $U K$
}

\author{
Pauline Weetman, Department of Accounting and Finance, University of \\ Strathclyde, Glasgow, UK
}

\section{Introduction}

There is a challenge for those who set standards for professional practice to persuade constituents as to the acceptability of those standards. Previous research (Young, 2003) has explored the rhetorical strategies observed in accounting standards to construct and persuade as to what is "good" and to silence potential criticisms and alternative proposals. We extend that research by considering the sequence of rhetorical strategies observed in a controversial situation in auditing that required two exposure drafts prior to arriving at a standard. Our contribution is to relate this sequence of rhetorical strategies to the opinions expressed in published letters of comment on the exposure drafts and to the changing position taken by the standard setter. This allows us to explore in more depth the ways in which the rhetoric of the standard setter in published documents responds to comment in the public domain. We address in particular the development of Statement of Auditing Standards SAS 130 The Going Concern Basis in Financial Statements (APB, 1994) from two exposure drafts $(\underline{\mathrm{APB}, 1992 \mathrm{a}}, \underline{1993 \mathrm{a}})[1]$.

Our motivation for choosing the development of the UK auditing standard on "going concern" is derived from the significant debate about the extent to which auditors should take an active rather than a passive role in identifying companies at risk. The role of the auditor in evaluating the going concern status of a company was given prominence by the recommendations of the Cadbury Committee (Cadbury, 1992) and the parallel implementation of these recommendations by the Auditing Practices Board (APB) and by a Going Concern Working Group (GCWG)[2]. Initially, the APB proposed[3] more thorough assessment of the going concern basis, the auditors' assessment to cover a longer period, and fuller disclosures by the auditors.

These proposals appeared to address concerns expressed in the literature that the previous guidance $(\underline{A P C}, 1985)$ gave auditors a passive rather than an active role. However, the GCWG did not favour the longer period of assessment by the auditor because that would impose a greater burden on directors. The ensuing debate culminated in SAS 130 (APB, 1994) in which the period covered by the auditors' assessment was reduced to its previous level, the auditors' activities in assessing the going concern basis were effectively reduced to the previous level, and any increased disclosures were provided by directors rather than by auditors. Our research question is: $R Q 1$. How does the rhetoric of the standard setter respond to comments received during the development of a standard, initially defining and then neutralising a more 
active role for auditors? Our analysis reflects the quasi-legal nature of an auditing standard and the particular forms of rhetoric available to those writing such a standard. Previous research into accounting writings has applied linguistic analysis in different forms of writings where there is a wider choice of discursive style available. For example, Cooper and Puxty (1994) use the post-structuralist insights of Barthes to show how the reader can disrupt a text by active reading, taking as their example a magazine article on an accounting subject. This means that the communicative effectiveness of the text depends on the reader as well as on the intentions of the writer. Arrington and Francis (1989) apply deconstruction, following Derrida, to a research text in positive accounting theory in order to question the positive theorists' claims to privilege their work. Evans (2004) applies theories of linguistics to consider the problems of translating accounting terminology across languages and cultures.

In focusing on the text of standards we recognise one of the three directions for research proposed by Fogarty et al. (1994). They concluded that future research into US financial accounting standard setting should investigate the role of power in standard setting, the ideology of standards with reference to the emergence of current institutional arrangements, and the texts produced in the standard setting process, using the traditions of rhetorical analysis.

In the next section we discuss the nature of rhetoric and the ways in which analysis of rhetoric may be applicable in the case of a quasi-legal text such as an auditing standard. That is followed by a description of key stages in the development of a UK auditing standard on going concern. An explanation of the method of analysis and data sources is followed by analysis of opinion letters submitted to the APB, drawing out the key issues and challenges identified. We then trace the reaction to these issues and challenges in the changing rhetoric of two exposure drafts and the final standard. We reflect Young (2003) in categorising the rhetorical strategies of the three documents under the headings of "constructing and persuading" and "silencing alternatives". We conclude with policy-related observations.

\section{Rhetoric}

Rhetoric is the art of persuasive discourse (Cockcroft and Cockcroft, 1992). The practice of rhetoric derives from ancient studies of political oratory but it has an important modern resonance. Cockcroft and Cockcroft (1992, p. 3) cite Aristotle in support of their view that rhetoric is defined by its unique breadth of application and by its adaptability to new subject areas as they evolve. Discourse is often functional (Potter and Wetherell, 1987), being designed to be persuasive, to win hearts and minds. The study of rhetoric is, in part, the study of persuasive work and the organization of discourse to that end (Wetherell et al., 2001a, p. 17). Billig (1987) views rhetoric as a dialogue rather than a monologue. In his view every argument or generalisation invites a counter-proposal from the individual or group envisaged as the audience. Language use is interactive, addressed to others and responding to what has gone before. The analyst interested in rhetorical work may aim to identify the positions and arguments being addressed or countered (Wetherell et al., 2001b).

The question arises as to whether rhetoric can be observed in a document such as an auditing standard which, is in essence, a technical guide. Fairclough (1995, p. 185) makes the general case for the analysis of text and texture in critical discourse 
analysis. He argues (Fairclough, 1995, p. 186) that part of the task of critical discourse analysis is to contribute to the development and spread of a critical awareness of language as a factor in domination. Young (2003) has demonstrated evidence of rhetorical devices used as means of persuasion in accounting standards.

In examining the texts of auditing standards for evidence of rhetorical devices, we echo Young (2003, p. 624) in noting that standards are "serious texts" emphasised by the use of formal language. They are directed at an audience of experts and the standard-setter is seeking acceptance by that audience. Throughout the standard setting process the standard setter has engaged with critics and attempted to persuade them to agree to the simple plot that a particular aspect is broken in particular ways and the standard will fix these breaks. The engagement with critics means that the standard will be responding in some way to their views, either to reject the arguments or to persuade towards agreement. The seriousness of the texts means that the range of rhetorical devices available may be constrained - for example, we would not expect to find the range of metaphor or allegory described by Walters-York (1996) in the formal prescription and guidance sections of a standard. Our search for rhetorical devices reflects the constraints on a "serious text", although it could be said that "going concern" is itself a metaphor, standing for perceptions of a business that range from an emerging concern about the risks attached to continuation of funding through to acknowledgment of a state of insolvency.

Rhetorical devices are categorised in Cockcroft and Cockcroft (1992) under four main headings of lexical choice, sound patterning, figurative language (also called trope) and schematic language (see Appendix). Lexical choice refers to choosing words, particularly where synonyms may carry different nuances of meaning. Sound patterning creates and enhances meaning by devices such as alliteration or rhyme. Figurative language turns meanings by way of a less direct mode of expression. Examples of figurative language are allegory, allusion, irony, metaphor, metonymy and personification. Schematic devices cover a wide range of usage of words, including antithesis, word-play and puns, syntactic devices, repetition, amplification and diminution, and ploys such as open questions or question and answer. There is no comprehensive list because the devices used are selected to match the context in which persuasion is to be exercised. In this paper we draw on the list of such devices identified by Cockcroft and Cockcroft (1992, pp. 158-61.)

We expect in a "serious text" such as an auditing standard that the opportunities for figurative language may be limited or nonexistent in the formal text but they may be found in the accompanying explanatory material. The use of figurative language reflects Aristotle's ethos (persuasion through personality and stance) and pathos (persuasion through the arousal of emotion). We do expect to find in the "serious text" examples of schematic language, drawing on Aristotle's logos (persuasion through reasoning). Cockcroft and Cockcroft (1992, p. 116) cite legal documents as examples of non-literary language where logos determines lexical choice. To reflect the nature and purpose of auditing standards we connect the dialogic structuring of persuasion, described by Billig (1987), with the structuralist views of de Saussure (1974) to analyse informal and formal use of language in persuasion.

We draw on, and seek to refine, the analysis of Young (2003) who demonstrated that FASB accounting standards employed rhetorical strategies that construct a standard as 
good, attempt to persuade us that the standard is "good", and silence alternatives and possible criticisms of the standard. She shows that a "good" accounting standard is constructed by appealing to reality as an authority and to users as authority, by making claims to consistency and by invoking the practical. Silencing alternatives is achieved by presenting and then disposing of criticisms and by placing objections and criticisms within a negative framework of qualities opposite to those of a "good" standard. The standard-setting Board also presents itself as a "good" standard setter and establishes itself as the arbiter of a deliberative, rational process among the parties involved. The use of structure and argument as persuasive strategies in UK standard setting is documented in Warnock (1992) who analyses the explanatory notes contained in UK accounting standards.

\section{Going concern developments}

The first UK auditing Guideline on going concern was issued in 1985 by the Auditing Practices Committee (APC, 1985). (At that time a Guideline indicated good practice but did not have the mandatory status of a standard.) It stated:

If during the course of his audit the auditor becomes aware of any indications that the going concern basis may no longer be valid, he should carry out the additional procedures outlined in this guideline. If the auditor's procedures reveal no such indications, it will be reasonable for him to accept that the going concern assumption is appropriate (APC, 1985, para. 6).

The first US auditing standard on going concern, issued by the American Institute of Certified Public Accountants (AICPA, 1981) took a similar approach in stating that:

[...] the auditor does not search for evidential matter relating to the entity's continued existence because, in the absence of information to the contrary, an entity's continued existence is assumed in financial accounting (AICPA, 1981, para. 3).

Both the UK Guideline and the US standard were described by critics as presenting an essentially "passive" approach because neither appeared to require auditors to take the

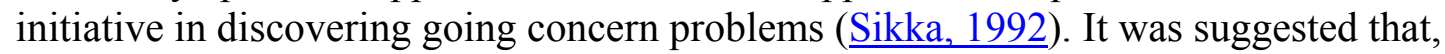
in the wake of highly embarrassing and publicised collapses of major corporations audited by major UK audit firms (Sikka, 1992), the profession had responded by reducing its responsibilities with respect to going concern issues (Humphrey et al., 1993). More generally, Pong and Whittington (1994, p. 172) reviewed a selection of the UK auditing guidelines issued in the 1980s and concluded that these:

[...] did not attempt to re-think or extend the scope and technique of the audit. Rather, they attempted to consolidate the status quo, and, in particular, to limit the obligations and responsibilities of the auditor.

Under the APC's Guideline on going concern, auditors who had doubt about the going concern status of a company presented a qualified audit report using "subject to" wording. Nevertheless, companies continued to fail shortly after receiving an unqualified audit report (Citron and Taffler, 1992). This was one of the concerns leading to the establishment of the Cadbury Committee[4] (Cadbury, 1992, para. 2.2), which proposed that the auditor should take a more active role in testing "going 
concern" assumptions (Cadbury, 1992, para. 5.18). The Committee recommended that directors should state in the report and accounts that the business is a going concern, that the auditors should report on this statement and that the accountancy profession, in conjunction with representatives of preparers of accounts, should take the lead in developing guidance for companies and auditors (Cadbury, 1992, para. 5.22).

A Going Concern Working Group [5] (GCWG, 1994) was established by the Institute of Chartered Accountants in England and Wales, comprising seven members representing auditors and preparers of accounts. Problems were encountered in defining the minimum period of the "foreseeable future"[6] for evaluation of going concern status. The definition of the minimum period is important to directors and auditors because it defines the period for which directors must prepare budgets or forecasts to demonstrate going concern capacity. The GCWG favoured looking forward to the end of the accounting year, in line with existing practice (APC, 1985), while the APB preferred to extend the minimum period to require budgets or forecasts for a period of 12 months from the date of signing the annual report[7].

Without waiting for the GCWG to report, the APB issued an exposure draft of an auditing standard in May 1992 (APB, 1992a), alongside an exposure draft of a new standard on audit reporting (subsequently SAS 600) (APB, 1992b). These two exposure drafts together were seen as marking a determined effort to bridge the expectation gap by extending auditors' responsibilities in relation to the going concern problem (Accountancy, 1992). It was envisaged that auditors would refer in their reports to inherent uncertainties affecting the accounts. Consequently, SAS 600 Auditors' Reports on Financial Statements (APB, 1993b) changed the audit emphasis, in matters of doubt about a going concern, from qualified opinion to explanation of status. This change reflected concerns that a qualified opinion might be a potential source of confusion to users of financial statements (Asare, 1990; Sikka, 1992; Citron and Taffler, 1999).

In May 1993 the GCWG produced draft recommendations to directors that they should consider budgets and forecasts covering the period to the next balance sheet date as a minimum (Accountancy, 1993). Despite the apparent contradiction between the GCWG's advice to directors and the APB's advice to auditors, the APB issued a second exposure draft on going concern in December 1993 (APB, 1993a), retaining the stricter requirement for auditors to look forward a minimum of 12 months from the date of signing the audit report, and to obtain an assertion of going concern status [8] from directors covering that period (APB, 1993a, para. 18). The APB claimed its proposals responded to "clear public expectations" (Accountancy, 1994).

The parties were urged to compromise in order to take matters forward (Gold, 1994)[9]. In their final versions, both the GCWG and the APB gave directors the discretion to decide whether additional disclosure is needed if the period considered is less than 12 months from the date of signing the financial statements. The compromise on directors' and auditors' responsibilities is seen in the close alignment of the wording of the GCWG (1994, paras. 16 to 20) and that of paras. 9 to 13 of SAS 130 (APB, 1994).

The sequence of developments relating to the going concern audit has been interpreted as a silent game between directors and auditors where both parties were 
net gainers (Masocha and Weetman, 2005). Table I summarises the key events and dates.

When SAS 130 was issued, the chairman of the APB's Going Concern Task Force which prepared the standard commented (Boyd, 1994):

The APB originally issued an exposure draft on the subject [of going concern] in May 1992, and there was a subsequent re-exposure in December 1993. There has been much public debate, during this period, over what was perceived as being an extension of auditors' responsibilities at a time when there was much discussion within the profession on limitation of liability.

SAS 130 supersedes the existing auditing guideline, The Auditors' Consideration in Respect of Going Concern. Auditing guidelines are persuasive rather than prescriptive. The publication of a SAS, therefore, upgrades the status of the material considerably. The auditing guideline was often criticised, perhaps unjustly, for seeming to recommend that auditors take a passive rather than an active role when considering the applicability of the going concern basis. SAS 130 requires auditors to consider the entity's ability to continue as a going concern and any relevant disclosures in the financial statements when considering whether they give a true and fair view...

Boyd's commentary shows that the APB was aware in 1994 of the continuing significance of the "active/passive" debate that originated with the 1985 Guideline (Sikka, 1992). Boyd's observations hint at a more active approach but stop short of a specific assertion. This leaves scope on the one hand to reassure the auditing profession regarding any extension of liabilities. This is achieved by the words "...what was perceived as being..." which point the reader towards the view that the perception was ill-founded. Boyd leaves scope on the other hand to reassure those seeking a firmer approach by explaining the technicalities of upgrading from a guideline to a standard.

We explore the ways in which the rhetoric of two exposure drafts and the resulting standard persuaded one set of interested parties of the appearance of an active approach while persuading another set of interested parties of the reality of an effectively passive approach, unchanged in substance from the 1985 position criticised by Sikka (1992).

\section{Approach and data sources}

The stages of answering this question are:

1. How did the rhetoric of the APB's first exposure draft promote encouragement for a more active audit approach to going concern?

2. How did the rhetoric of the APB's second exposure draft respond to criticisms of the first?

3. How did the rhetoric of the final SAS 130 respond to the criticisms of the second exposure draft? 
Our data sources are the texts of two published exposure drafts and one auditing standard, and the letters of comment submitted to the APB on each of the exposure drafts. We denote the exposure drafts as "ED1" (APB, 1992a) and "ED2" (스, 1993a)[10]. They resulted in the UK standard SAS 130 (APB, 1994).

The letters of comment submitted to the APB in response to each of the exposure drafts are filed on the public record[11]. Ideally, we would also like to explore the views of those who commented privately to the APB, and the deliberations of the APB on the submissions received but, unfortunately, such information is not available.

It may be seen from Table II that the responses, by volume, were dominated by auditors.

That is perhaps not surprising in a request for comments on an auditing standard. However, it meant that those potentially affected by the proposed standard, particularly company directors, users of financial statements, and the wider public interest, were not well represented in the responses.

\section{Issues in comment letters}

Responses on both EDs took a relatively open format in the nature and sequence of items covered. This is because the Invitations to Comment accompanying both documents were worded in general terms, inviting comments from those who agreed as well as those who disagreed, without setting specific questions. A further complication was that a separate exposure draft on audit reporting (APB, 1992b) had been issued by the APB at the same time as ED1 ( had included both sets of comments in one letter and had even dovetailed the responses. We therefore used the APB's own themes as the basis for analysis. These are: more thorough assessment of the going concern basis; the auditors' assessment to cover a longer period; and fuller disclosures.

Reflecting the APB's themes, we found three recurring themes in the comment letters, namely: the requirement for a written statement from company directors (as an essential component of the more thorough assessment), the expected horizon of the "foreseeable future" and the general thrust of moving to a more active role for auditors[12].

\section{Written statement from directors}

ED1 proposed that a written statement should be obtained from directors. Table III shows that support for this proposal was in the minority, although relatively strongest in the professional accountancy bodies. Practical considerations were the most frequently cited problem, along with the question of whether an auditing standard could impose a requirement on directors. A third consideration was the difficulty of obtaining information from banks to allow directors to provide the necessary statement. Two of the major accountancy firms confused the picture and raised potential alarm by pointing with apparent approval towards the more rigorous requirements placed on directors when giving a statement of the adequacy of working 
capital in a prospectus. The spread and number of responses changed very little in the comments on ED2, indicating that the concerns remained largely unaddressed.

\section{Foreseeable future}

ED1 proposed that the assessment of going concern status should be based on a "foreseeable future" of at least one year from the date of signing the audit report (Table IV). Previously, in the 1985 Guideline (APC, 1985), the minimum period was one year from the balance sheet date. The objections to this interpretation of the "foreseeable future" in ED1 were predominantly based on the practical problems of making projections beyond the next balance sheet date, but there were also concerns expressed about the problems of obtaining confirmation from a bank of the continuity of borrowing facilities. It was pointed out that some banks wait to see the audited accounts before confirming the continuation of facilities. In the comments on ED2 the concerns about practical problems remained but the concerns about bank confirmations had largely disappeared. Many of the responses on ED2 urged the APB to align its recommendations with those of the GCWG.

\section{A more active role for auditors}

The Cadbury committee was clearly looking for a more active role for auditors in identifying going concern problems and this was recognised by some limited support in the comment letters (Table V). Objections to the more active role for auditors focused on the extension to the liabilities of auditors and directors and on the additional costs that would fall on audit clients. The support for the active approach declined in the second round of comments, compared to the first.

\section{Structure of exposure drafts and standard}

We now explain the general structure of the two exposure drafts and standards before analysing in detail the rhetorical strategies used in constructing each document, in persuading the reader to accept the document, and in silencing opposition.

When the Auditing Practices Board (APB) published an exposure draft in the 1990s, its normal procedure was to use a Preface and Invitation to Comment to introduce the prescriptive and explanatory sections. The final standard carried no explanatory Preface and no appended explanation of the type found in the Basis for Conclusions analysed by Young (2003) using FASB accounting standards. However, it was the usual editorial practice at the time to publish a short article in the journal Accountancy (the UK monthly professional journal where official material, such as a new auditing standard, was announced to members of the Institute of Chartered Accountants in England and Wales). The short article was written by a member of the team involved in producing the standard, although with the usual disclaimer that the opinions were those of the author only. We have therefore used the short article (Boyd, 1994) published with SAS 130 as the equivalent of the "Basis for conclusions" of a FASB standard.

At the start of each SAS it was explained by the APB that Statements of Auditing Standards contained basic principles and essential procedures indicated by paragraphs in bold lettering, with which auditors were required to comply in the conduct of any 
audit. It was further explained that SASs also included explanatory and other material designed to assist auditors in interpreting and applying auditing standards. The explanatory material, in non-bold lettering, was found in sections following each of the bold-type paragraphs. Appendices to the standard gave examples of applications.

It could be argued that the structure of the standard is the first rhetorical device observed. The dispersed placing of the bold-type paragraphs, each followed by the reassuring interspersion of the "grey letter" explanatory paragraphs, could persuade the auditor that this is essentially a "principles-based" standard where interpretation and application are matters for the judgment of the expert. At the same time the existence of the explanatory paragraphs could persuade other readers that auditors did not have unfettered scope for interpretation of the standard[13].

In the next sections we discuss in detail the rhetorical devices used in the exposure drafts and the auditing standard on going concern, following Young (2003) in using the headings "constructing", "persuading" and "silencing". Each rhetorical device identified is italicised in the text and is explained in the Appendix. Our analysis shows how the rhetoric adapts to deal with the opinions on each exposure draft, as summarised in Tables III, IV and V.

\section{Constructing and persuading}

Young suggests (Young, 2003, p. 625) that the constructive and persuasive work begins with the opening summary. This seeks to establish the standard as a "good" standard. We discuss the rhetorical devices used in the Preface to each Exposure Draft, where some flexibility of expression is possible. For SAS 130 we look to the explanations provided by Boyd (1994) as chairman of the group that prepared the standard for the APB. We then move to the more restrictive environment of the boldletter prescriptive paragraphs and the grey-letter explanatory sections of the exposure drafts and the standard.

\section{Prefaces}

For the two exposure drafts, ED1 and ED2, the persuasive effort is particularly concentrated in the Preface of each. The "good" features are emphasised in an appeal to the public interest, by an explanation of how changes will bring improvements and, in ED2, through an apparent response to concerns expressed in consultation.

Public interest. ED1 starts with an assertion of the public interest: "Public interest" is an example of metonymy (where the name of a group is substituted for those persons in the group). Here it persuades the reader to identify with the collective description without requiring identification of the persons concerned. This metonymy is frequently used in regulatory processes and is highly persuasive because the reader is discouraged from challenging the needs of this potentially infinite group of persons:

There is evidence that the public interest would be best served by the inclusion of fuller information about risks facing companies, especially of business failure, in audited financial statements intended to give a true and fair view (APB, 1992a, Preface 1)[14]. 
The phrase "there is evidence" is an example of the rhetorical device of referring (showing supreme confidence by referring a matter to the audience as self-evident). "Fuller information" is an example of a comparison where the present document is presented favourably in relation to some other (unstated) possibility. "Risks facing companies" is a further metonymy that embraces a potentially broader agenda than the going concern debate, bringing the reader back to the subject in hand by citing a specific example of risk as business failure.

Paragraph 2 of the Preface to ED1 establishes the role of the APB as the guardian of the public interest in the first sentence. The second sentence links this guardianship to disclosure about going concern status by a strategically placed "thus":

The view of the Auditing Practices Board ("the Board") is that the public should receive this fuller information. The main aim of this proposed Statement of Auditing Standards ("SAS") is thus [emphasis added] to help ensure that doubts about the going concern presumption are detected and adequately disclosed in financial statements and auditors' reports. This should enable users of financial statements to assess for themselves the impact of any major uncertainties and the consequent risks to the viability of the company. The Board believes that the need to make such fuller disclosures should also help to prompt directors to take action at an earlier stage to avoid business failure (APB, 1993a, Preface 2).

The paragraph introduces the APB as the body that will provide the remedy for the problem identified in paragraph 1 of the Preface. It uses the logos of the conjunction "thus" to persuade the reader that this "good" standard will bring benefits to users and preparers of financial statements. It uses metonymy in substituting "the Board" for the members of the Board. It is persuasive by implanting the impression that the Board has a collective authority beyond that of its individual members. It could be argued that "the view of the APB" is a persuasive metaphor since it is people, rather than Boards, who have views. Comparison is used again in repeating "fuller disclosures" to give a favourable tone to this document in comparison with an undefined alternative. Syntactic parallelism (use of a similar rhythm within the paragraph as a whole) is used in the rhythms of "... users to assess for themselves... directors to take action at an early stage..." to draw the attention of the reader to the balance of the intended improvements for both users and directors.

Change as an improvement. ED1 lists three "main areas of change" \{ED1 Preface, 4 and 5\} as: more thorough assessment of the going concern basis \{ED1 Preface, 4-9\}; assessment to cover a longer period \{ED1 Preface, 10-13\}; and fuller disclosures \{ED1 Preface, 14 and 15\}. In each case comparison ("more", "longer", "fuller") persuades the reader that an improvement is in prospect. Referring appears again in para.16 (" ... there appears to be ..."), suggesting an undefined general perception of concern (metonymy for those having the concern) that can then be explained:

There appears to be a general perception that, under current Auditing Standards and Guidelines, in the absence of any reference in the auditors' report, there are no doubts relating to the company's ability to continue trading as a going concern. This is not necessarily so. The proposed SAS therefore explains what can reasonably be expected of auditors in this regard (APB, 1992a, Preface 16). 
The Preface to ED1 concludes with a "Request for comments" in the form of a general invitation and open questions on five specific issues. The tone encourages a positive response:

Comments are most valuable if they include a statement of the overall degree of support for the proposals ... (APB, 1992a, Preface 20).

The set of questions also form a leading summary because it focuses attention on particular issues (and possibly away from others) even before the reader addresses the detail of the proposal. A leading summary also serves a silencing function by directing attention away from potentially contentious issues.

In drafting ED2 the APB was aware of the main objections summarised in Tables III, IV and V. Despite the objections the APB decided to hold firm to what it now described as the "main principles upon which the Board developed" ED1. The change of description from "main changes" in ED1 to "main principles" in ED2 is an example of lexical choice where the ethos moves to a more persuasive category, discouraging argument from the presumed audience by raising the status of the pronouncements.

Under the heading "the main changes to the 1992 exposure draft" the APB first of all leads the reader to question the effectiveness the Operating and Financial Review:

As mentioned in the preface to the 1992 exposure draft, the Board considers that it is highly desirable that the Accounting Standards Board ("ASB") should develop a Financial Reporting Standard which covers the treatment in financial statements of uncertainties (including those affecting going concern) and disclosures concerning them. The Board welcomes the "Operating and Financial Review" guidance issued by the ASB in July 1993. However, that guidance is non-mandatory and essentially deals with a review of past events. Accordingly, this new exposure draft contains guidance for auditors concerning the adequacy of disclosures in financial statements of uncertainties which affect the appropriateness of the going concern basis... (APB, 1993a, Preface 3).

There is antithesis between "welcomes", "however" and "accordingly" which seeks to establish support for the exposure draft by casting doubt on the efficacy of the OFR. That antithesis is used to mask the lack of an explicit link in content between the sentence criticising the limitations of the Operating and Financial Review (OFR) and the sentence explaining the content of the new exposure draft. It is not even entirely accurate to describe the OFR as "essentially ... a review of past events" since the OFR encouraged forward-looking information. Nevertheless, the antithetical comparison with the alleged deficiencies of the OFR is presented as a strategy in persuading the reader to accept the revised exposure draft.

Para. 4 of the Preface begins:

Views expressed in the letters of comment on the 1992 exposure draft raised several key issues which the proposed SAS addresses as follows, including: ... 
This could give the impression (in the assertion "...the proposed SAS addresses..." ) that the views contained in the letters of comment have been given due weight, although the detail of this paragraph gives no information on those views. There is no report on the nature or magnitude of the opinions contained in the comment letters. The absence of information silences potential challenges from readers.

Responding to concerns. The APB moves on to apply the rhetorical device of question and answer, which allows the APB to avoid responding to, or even acknowledging, the strength of opposition to ED1. The questions are all phrased in terms of apparent factual enquiry, for example:

What is the minimum future period for which auditors should seek evidence in forming a view as to the appropriateness of the going concern basis? (APB, 1993a, Preface 4a).

This apparently factual question gives no hint of the weight of opinion opposing the minimum future period proposed in ED1, as evidenced in the comment letters (see Table III). The answer to this question is:

The future period proposed in the 1992 exposure draft (that is, a period of at least one year from the date that the directors approve the financial statements) has been retained. However, there is now further guidance on the nature and extent of audit evidence available and what constitutes sufficient appropriate audit evidence (APB, 1993a, Preface 4a).

The response creates an impression that the future period is a settled factual issue rather than a matter of principle that might still be open for debate.

In separate paragraphs $\{$ ED2, Preface 8 and 9$\}$ the APB acknowledges its disagreement with the guidance in preparation by the GCWG for directors:

The working group does not currently intend to specify a minimum period which directors should consider (APB, 1993a, Preface 8).

The lexical choice "does not currently intend" invites the reader to doubt the permanency of this arrangement. There is an implication that the GCWG (described in the extract as "the working group") might eventually move towards a minimum prescription, in which case the APB's proposal would be more acceptable. Next we are presented with the APB's position:

By contrast, the Board believes - and this was an underlying principle of the 1992 exposure draft - that there is a clear public expectation that auditors will look at least to the first anniversary of the date on which the accounts are approved, that is up to the date the next set of financial statements are issued. The new exposure draft continues to reflect this view (APB, 1993a, Preface 9).

We see metonymy again in the use of "the Board", giving it the power of belief. We also see the use of referring in "clear public expectation" and the metonymy of "public expectation" all persuading the reader towards supporting this belief. There is 
syntactic parallelism in contrasting the stronger rhythm of "the Board believes" with the weaker one "the working goup does not currently intend". Even the use of capital letters for "the Board" and lower case for the "working group" is a means of depicting the relative strength of the APB's position.

It's good to make no change. In SAS 130 the APB made an about-turn and gave way to the GCWG in the specification of the foreseeable future. Despite the about-turn, SAS 130 contains no justification of its position and there is no mention of the compromise on the foreseeable future. However, the reference to the public interest has disappeared.

We explained earlier that there was no "Basis for Conclusions" section in the structure of APB standards. To discover the persuasive rhetoric supporting SAS 130 as a "good" standard we have to look to the separate statement by Boyd (1994) as the chair of the APB's Going Concern Task Force that produced SAS 130. His article was presented in the magazine Accountancy immediately ahead of the section containing the standard. It effectively acted as a preface or preamble without being labelled as such:

SAS 130 supersedes the existing auditing guideline, The Auditors' Consideration in Respect of Going Concern. Auditing guidelines are persuasive rather than prescriptive. The publication of a SAS, therefore, upgrades the status of the material considerably (Boyd, 1994).

The reader is now pointed away from the content and towards the status of the contents and "upgrades ... considerably". This argument of enhanced status did not appear in ED1 or ED2. By implication the content of SAS 130 was little changed from the 1985 Guideline, previously criticised as giving the auditor too passive a role. That was likely to be of concern to those who supported and welcomed the Cadbury Committee's proposal of a more active role for auditors. Boyd's article is considered further in the discussion of "silencing".

\section{Formal paragraphs in standard}

We explained earlier that the formal parts of the exposure drafts and standard comprise bold letter paragraphs containing basic principles and essential procedures, each followed by explanatory sections that expand on the basic principles.

The requirement of the Cadbury report was for a more active role for the auditor and so we focus on the lexical choice of verbs in the exposure drafts and standards as the main form of instruction or explanation of this more active role. We focus in particular on the verbs and their context because the process leading to the exposure drafts and standards emphasised a more active role for auditors. Verbs are the most direct way of indicating a more active role, although concern has been expressed about the verbs used in standards. Wong (2004), reporting a consultation carried out for the International Federation of Accountants (IFAC), reported particular concern about the conventions of standard setting, such as the use of "should" and "shall" to indicate mandatory requirements, and the problems these conventions might encounter in translation. In the responses on ED2 the Association of Certified Chartered Accountants (ACCA) expressed concern about the status of the verbs: 
The Board's objective of explaining a difficult subject as fully as possible has occasionally resulted in statements that are wordy and convoluted. Clarity is not helped by the use of the present tense in many of the explanatory paragraphs, which tend to make explanatory material read like a statement of fact. Paragraphs 19 and 34 provide examples of occasions when this material almost assumes the nature of an instruction and we trust that sufficient consideration has been given to the legal construction that may be put on the words at a later date.

The ACCA is pointing here to lexical choice as a rhetorical device of persuasion verging on instruction without being defined as such.

In analysing the nature of the verbs we use Saussure's concept of signifier and signified, viewed as rhetorical devices by Cockcroft and Cockcroft $(1992$, p. 10) who regard the thinking of de Saussure (1974) as an important element in the study of persuasive discourse. Saussure viewed language as functioning on two axes - the vertical, where the writer chooses a word from a range of options, and the horizontal, which is the syntactic relationship of words in a sequence. He introduced the idea of words as a sign, consisting of the signifier (sound or written symbol) and the signified (the meaning or concept). The actions are specified in verbs as the signifiers of the active approach. However the meaning of the verbs can be modified by their context, so that a signifier of an active approach may be signified as passive by the wider context. We categorise the verbs as prescriptive ("should"), descriptive (present tense) and permissive (modal verbs such as "may" or "could"). In the bold-type paragraphs the APB uses "should" as a prescriptive verb to denote an instruction (similar to the "shall" of FASB, as discussed by Young). In the non-bold grey letter section there are softer descriptive verbs such as " the auditors consider", "the auditors decide" and even softer permissive verbs "the auditor might ...", "the auditor could ..."

Verbs as signifiers of action. To measure the use of lexical choice in verbs as a persuasive factor, we counted all instances of verbs relating to any action attributable to the auditor. We searched the text (excluding Appendices) for "auditors" (or "they" and similar descriptions referring to auditors). We labelled each verb as a signifier in one of three categories: prescriptive, descriptive or permissive. We then read the verb in the context of the words that follow it or otherwise govern its application. We applied one of two categorisations of the qualifying words that follow the verb: either specifying an action to be carried out by the auditor, or giving discretion over the extent of an action.

Looking first to the signifiers, in ED1 we counted 23 prescriptive verbs compared to 14 that were descriptive and three that were permissive. In ED2 the prescriptive verbs were almost unchanged at 22 but the descriptive verbs increased to 40 and the permissive to 8 . These counts are consistent with the APC's claim that the principles were unchanged in ED2 but the amount of explanation was increased. There is a further persuasive aspect to the use of the present tense for description - it gives the impression that the practices described are already in operation and so new effort is not required. In SAS 130 the number of prescriptive verbs fell to 16 while the descriptive verbs decreased marginally to 36 . The permissive verbs increased to 22 , dominated by 9 "may" and 8 "might". It is not clear how these permissive descriptions help to improve a standard - they seem to be giving an indication to nonexperts of how an auditing expert might behave. 


\section{Signified meanings modify prescriptive verbs}

The essential function of the bold letter paragraphs is to construct the framework of principles of the standard. In these bold letter paragraphs the prescriptive verb "should" indicates an instruction. Focusing on the three issues that were the cause of most concern in the letters of comment on ED1 and ED2, we track the progress of these issues through the exposure drafts to the standard. Our analysis is based on de Saussure (1974), as explained earlier, to show that while the signifier remains apparently active, it is modified by progressively more passive signified meanings.

Written statement from directors. The first bold-lettered paragraph of ED1 deals with directors' statements. The same theme carries through to ED2 \{18\}[15] and SAS 130 $\{33\}$ but the wording changes:

Auditors should obtain a written statement from the directors: (APB, 1992a).

The auditors should request from the directors an adequate written assertion: ( $\underline{\mathrm{APB}}$, 1993a, p. 18).

The auditors should consider the need to obtain written confirmations of representations from the directors: (APB, 1994, p. 33).

ED1 $\{1\}$ increased the active obligation on auditors with a strongly worded lexical choice to "obtain" a written statement from the directors confirming their view that the company is a going concern. The responses to ED1 questioned whether this could be achieved because auditing standards have no jurisdiction over directors (see Table III). ED2 $\{18\}$ maintained the principle but changed the perception of an active audit through the lexical choice of a polite "request". SAS $130\{33\}$ dispensed with the overtly active, leaving substantial discretion with the auditor in the wording "consider the need to obtain". A signifier of an active process remained throughout in the use of "should" but the signified meaning became less active on each revision.

Foreseeable future. The same paragraphs specify the period of "foreseeable future":

The statement so obtained should have been drawn up having regard to circumstances which the directors consider may occur during a period of at least one year from the date they approve the financial statements, and to circumstances which they know will occur thereafter. Auditors should obtain from the directors the necessary evidence to support this view (APB, 1992a, p. 1).

... whether the assertion has been made having regard to circumstances which the directors consider may occur during a period of at least one year from the date they approve the financial statements. Where the auditors are unable to obtain a written assertion from the directors supported and made in this manner, the auditors should consider the effect on their report (APB, 1994, 1993a, p. 18).

In both documents the requirement for a 12-month period is imposed on the directors but ED2 admits of the possibility that the directors might not respond adequately. The specification of the length of the period does not change and the strength of the requirement is reinforced by adding the label (SAS 130.2) giving a stronger 
impression of the principled nature of the paragraph. At the same time ED2 $\{18\}$ responds to criticism of ED1 by giving the auditors discretion to "consider" the effect where directors do not provide the assertion requested. The strongly prescriptive "should obtain" is modified to a discretionary action in "should consider". "Should" as the signifier of compulsion is modified in its signified meaning.

In SAS 130 the insistence on the 12-month period disappears. A new sub-heading is introduced "Foreseeable future: guidance and inherent limitations in application". The key words here are "inherent limitations" acting as a leading summary which invites the reader to note and agree the detail of the subsequent four paragraphs discussing the inherent limitations. First of all, other documents (SSAP 2 and the Companies Act) are cited to share the responsibility for the problem:

In defining the going concern accounting concept, Statement of Standard Accounting Practice Number 2 ("SSAP 2") uses the term "foreseeable future" without further elaboration. Neither the Act nor accounting standards expand on that term in the context of going concern (APB, 1994, p. 9).

Next, the inherent uncertainty is revealed:

Any consideration involving the foreseeable future involves making a judgment, at a particular point in time, about future events which are inherently uncertain. The following factors are relevant.

(a) In general terms, the degree of uncertainty increases significantly the further into the future the consideration is taken. The manner in which the uncertainty increases with time depends on the circumstances of each particular entity.

(b) Any judgment about the future is based on information available at the time at which it is made. Subsequent events can overturn a judgment which was reasonable at the time it was made (APB, 1994, p. 10).

This paragraph uses a logical structure $(\log o s)$ to establish in the mind of the reader a negative association between the quality of judgment and the length of the foreseeable future. The lexical choice of "overturn" is particularly negative.

The argument concludes by leaving the reader with doubts about the value of any judgment about the future. Logical links are emphasised by the words "accordingly" and "as a consequence":

Accordingly, the foreseeable future depends on the specific circumstance at a point in time, including the nature of the entity's business, its associated risks and external influences (APB, 1994, p. 11).

As a consequence, it is not possible to give any certainty in relation to going concern. Any judgment made, whether by directors or auditors, although reasonable at the time, can be valid only at that time and can be overturned by subsequent events (APB, $\underline{1994}$, p. 12).

In the instructions on procedures the wording becomes: 
$[\ldots]$ having regard to the future period to which the directors have paid particular attention in assessing going concern, the auditors should plan and perform... (APB, 1994, p. 21(b)(ii)).

This is an example of verb-based variation. In ED1 and ED2 the main verb is "occur" with the time period appended as an adverbial phrase. The emphasis in each ED is on persuasion to accept the time period as part of an instruction. In SAS 130 the time period is now moved to a subordinate clause, preceding the main verbs that draw attention away from the time period by focusing on the audit activity of "plan and perform". The syntactic structure is now diverting the attention of those who might remain concerned about the longer time period.

A more active role for auditors. The second bold-letter paragraph of ED1 relates to the audit planning process using words that indicate an active audit process:

... [the] auditors should plan and perform procedures specifically designed to identify

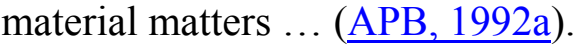

Similar words appear in ED2 $\{24\}$ and SAS $130\{21\}$. However, the nature of the "material matters" changes:

[...] material matters which might cast doubt on the directors' view that the company is a going concern ( $\underline{\mathrm{APB}, 1992 \mathrm{a}})$.

[...] material matters which could indicate concern as to the directors' considered view as to whether it is appropriate for the directors to adopt the going concern basis in preparing the financial statements (APB, 1993a, p. 24).

[...] material matters which could indicate concern about the entity's ability to continue as a going concern (APB, 1994, p. 21).

From ED1 $\{2\}$ to ED2 $\{24\}$ there is a change from "cast doubt on the directors" view" into the stronger negative wording of "indicate concern as to the directors" considered view". In SAS 130 we see another example of metonymy where the doubt or concern about the directors' view is transformed into a concern about "the entity". In the context of reducing expectations of an active approach from the auditors, removing specific reference to directors reduces the risk of reminding readers of the need to control directors through the audit process.

\section{Signified meanings modify descriptive and permissive verbs}

In the non-bold grey letter section there are softer descriptive verbs such as " the auditors consider", "the auditors decide" and even softer permissive verbs "the auditor might...", "the auditor could...". We noted earlier the concern expressed by the ACCA about the status of these descriptive verbs in its response on ED2. The use of present tense descriptions could be lexical choice that gives the appearance of instruction or at the very least gives the appearance of an habitual practice that is not open to question. 
We applied one of two categorisations of the qualifying words that follow the verb: either specifying an action to be carried out by the auditor, or giving discretion over the extent of an action. Examples are:

[...] the auditors describe the matters giving rise to their concern; (APB, 1993a, p. 41) (descriptive verb "describe", specific instruction on what is to be described).

In order to satisfy themselves as to whether it is appropriate for the directors to adopt the going concern basis; (APB, 1993a, p. 12) (descriptive verb "satisfy", discretion in the interpretation of "appropriate").

[...] depending on the circumstances ... auditors might be involved in assisting the directors in arriving at their own view; (APB, 1993a, p. 11) (permissive verb "might be involved", discretion in judgment of "depending on the circumstances").

[...] auditors may need to examine some or all of the following matters; $\{$ ED2, 26\} (permissive verb "may need", discretion in judgment of "some or all").

In total, we counted 27 signified meanings of specific action in ED1 compared to 13 signified meanings giving discretion to the auditor. In ED2 there were 35 signified meanings of specific action and 35 signified meanings giving discretion to the auditor. The increased proportion of discretion given in ED2 is an indication of the APB's concession to auditors in the context of not relenting on the essential principles but reassuring them that their professional judgment is not being eroded.

In SAS 130 we counted 39 specified actions and 35 discretionary actions. The total numbers do not change significantly from ED2 but there is some redistribution of the discretionary actions away from the descriptive verbs and towards the permissive verbs. The combination of permissive verbs and discretionary action gives the auditors the impression of even more scope to exercise judgment although it may be rather confusing to other readers who expected a more active audit approach to emerge from the process.

Our conclusion from this analysis is that the increase in discretion afforded in ED2 compared to ED1 was a strong signal to the auditing profession that the move to an "active" role was not as active as had been feared from ED1. Effectively, the discretion returned the auditors to a position close to that enjoyed in the 1985 Guideline. However, even this signal of a less active approach was insufficient to mute the opposition, leading to further criticism of ED2 as shown in the analysis of comment letters, and the eventual capitulation in SAS 130.

\section{Silencing}

Young refers to the "basis for conclusions" of FASB standards for evidence of the ways in which the FASB silences other possibilities and criticisms. We cannot replicate that analysis directly because it was not the habit of the APB to present such a discussion of its thinking as part of the standard. As explained earlier we look instead to the Preface to ED2 and to the chairman of the APB's Going Concern Task Force (Boyd, 1994) writing in the professional journal Accountancy to accompany the text of SAS 130. 
The significant distinction is that ED2 sought to silence those who were requesting a shorter period of foreseeable future and a reduction in auditor obligation, while SAS 130 sought to silence those who were supporting the longer period of foreseeable future and an enhancement of auditor obligation.

\section{Silencing the "passive": ED2}

We have already explained how the Preface to ED2 used the question and answer device, to avoid disclosing the extent of disagreement with ED1 while attempting to deal with that disagreement in the explanations. ED2 also tries to reassure auditors that there is no major increase in active approach, for example:

The degree of detail required in order to constitute sufficient appropriate audit evidence varies depending on the auditors' judgment in the circumstances ( $\underline{A P B}$, 1993a, p. 23).

The silencing strategies of ED2 complemented the silencing strategy of ED1 in its use of a leading summary, as explained earlier.

\section{Silencing the "active": SAS 130}

The APB lost its battle for a more active approach to the going concern audit. In the standard SAS 130 (APB, 1994) there is no obligation to obtain a statement from directors in all circumstances, there is no minimum period required for the foreseeable future and the reporting responsibility rests on directors, with auditors confirming the appropriateness of the directors' application of the going concern basis. The Introduction to SAS 130 is terse and comprises only two paragraphs, the second of which is a bold-type prescription. Specific mention of the Board has disappeared, along with the public interest; all that remains is an inanimate "SAS":

The purpose of this SAS is to establish standards and provide guidance for auditors in respect of their consideration of the going concern basis in financial statements prepared by directors (APB, 1994, p. 1).

When forming an opinion as to whether financial statements give a true and fair view, the auditors should consider the entity's ability to continue as a going concern, and any relevant disclosures in the financial statements (APB, 1994, pp. 1 and 2).

Applying the interpretation offered by Young (2003, p. 626) the disappearance of the Board is a means of distancing it from the actions recommended by the standard. The establishment of the SAS as an authority in its own right (metonymy) is a means of suggesting that auditing exists apart from its human creators and this impression is reinforced by placing a bold-type statement of principle within the "introduction". It is also reinforced by the legal style of labelling the statement of principle as "(SAS 130.1)"

For further evidence of silencing the active we turn to Boyd (1994) as the Chairman of the Task Force that prepared SAS 130. The justification for the standard is now drawn from the report of the Cadbury Committee on Corporate Governance (Cadbury, 1992): 
The APB believes that SAS 130 achieves the Cadbury Committee's objective "that as a fundamental concept of accounting the going concern principle should be conscientiously applied and that new guidelines should be developed...[that]... strike a careful balance between drawing proper attention to the conditions on which the continuation of the business depends and not requiring directors to express ... reservations that could of themselves jeopardise the business.

In this way the potential for objection on behalf of the public interest (brought to the fore in ED1 and ED2 as justification for a more active audit role) is silenced by a new concern for the wellbeing of the business. There is also reassurance for auditors that "active" is constrained within bounds set by the directors:

Although the SAS requires auditors to take an active role, the basis for the auditors' procedures is primarily the information on which the directors have based their own assessment and the reasoning behind it.

Boyd addressed an imagined audience of critics by first of all defending the 1985 Guideline:

The auditing guideline was often criticised, perhaps unjustly, for seeming to recommend that auditors take a passive rather than an active role when considering the applicability of the going concern basis.

He then described the role of SAS 130 without reference either to the period of foreseeable future or to the relative activity of auditors:

SAS 130 requires auditors to consider the entity's ability to continue as a going concern and any relevant disclosures in the financial statements when considering whether they give a true and fair view.

The reduction in the foreseeable future is explained by Boyd as:

The Joint Working Group and the APB have agreed that it is not possible, in fact, to specify a minimum length for this period.

The use of "in fact" is redundant to the sentence but silences those who might question an opinion from these two authorities. It discourages the reader from questioning the agreed view of the two parties involved.

The article then provides various assurances that there will not be significant additional burdens imposed on auditors by the standard. In a single document the rhetoric silences those who are concerned that the standard is not an active one and it silences those who are concerned that it is an active one.

\section{Conclusion}

We have applied analysis of rhetoric, drawing on and refining the approach in Young (2003), to explore in depth the ways in which the rhetoric of the standard setter responds to comments received during development of a standard by way of two exposure drafts. 
Both exposure drafts made use of figurative language as a rhetorical device in the Preface section. However, the aim of ED1 was to persuade the parties towards a more active approach. The aim of ED2 was to maintain the principles of the more active approach but persuade the participants that the reality would be no more active than the previous situation. A significant aspect of the Preface to ED2 was the "question and answer" section, which avoided disclosing, or responding to, the strength of opposition while selecting the agenda for the responses. The standard SAS 130, in changing the principles and watering down the practice, avoided any specific explanatory material and turned to persuading through a related publication. Here, the public interest gave way to the wellbeing of tbe business. The principles of ED2 gave way to the status of the standard as an improvement on previous guidance.

The first exposure draft issued (ED1, APB, 1992a) contained a robust set of instructions in the form of standards with supporting notes. In the prescriptive and explanatory paragraphs it had relatively little interactive dialogue with the audience. The second exposure draft issued (ED2, APB, 1993a) modified the wording of ED1, while retaining what the APB described as the three underlying principles. It attempted to silence the opposition to the underlying principles by offering increased explanations describing the actions taken by auditors and making explicit the discretion available within the standards. In offering more explanations than ED1, ED2 had more interaction with those who might question its recommendations. However, this was not sufficient to silence the opposition, as seen in the responses to the second exposure draft.

Countervailing pressure on the APB, from the GCWG and its supporters, forced the APB to retreat to a compromise position that sacrificed two of the underlying principles and obfuscated the third. It then became necessary for the standard SAS 130 (APB, 1994) to silence those who were still seeking the reforms attempted in the first exposure draft (APB, 1992a). This was achieved by rewording the relevant "standard" paragraphs without explanation in the preface and without any statement of the basis on which changes were made. In relation to the active part of the auditor's investigation, although the signifiers were active across all documents, the signified moved in a less active direction at each revision.

The rhetoric of the "public interest" as a driving force of the first and second exposure drafts disappeared entirely from the final standard. Effectively, the audit changes envisaged in the Cadbury report were neutralised in respect of auditors' involvement in warning of going concern risks.

The contribution of our research is to increase the explanatory power of the analysis by adding more specific textual analysis to Young's framework and relating the textual changes to the balance of opinion as expressed in published letters of comment. There are limitations in the subjective nature of the textual analysis, particularly in distinguishing the signified intent of the descriptions and permissions relating to audit actions, but such subjectivity is a feature of any text analysis of this type. The research also points to the limitations of the process of consultation used by standard-setters, based on exposure drafts. It is apparent from Tables III, IV and V that although the process of consultation through exposure drafts could be claimed to allow for opinions to be expressed as part of due process, it is highly debateable as to whether these exposure drafts effectively test public expectations at first hand. The 
evidence in those tables points to responses emanating largely from the auditing profession.

One policy implication of this paper is to question the effectiveness of testing the "public interest" by a due process of consultation, which targets primarily those whose actions are under scrutiny from a public interest perspective. The criticism could be taken back to the Cadbury Committee, in allowing the auditors and preparers of accounts to take charge of their own destiny and to the Hampel Committee in endorsing the success of this guardianship. It will be interesting to see how the UK's new oversight regime under the Financial Reporting Council (FRC) and Public Oversight Board for Accountancy (POBA, available at: www.asb.org.uk/poba/) changes the balance of arguing for the public interest, and in particular whether there is greater openness in making public the deliberations of the standard setting bodies. There is a also a question over how effectively the public interest can influence standards created at an international level when even the national consultation does not appear to raise a voluble challenge from the wider perspective.

\begin{tabular}{ll}
\hline Year & UK developments \\
\hline 1971 & SSAP 2 (ASC, 1971) classifies going concern as a fundamental accounting concept. Used \\
the term "foreseeable future" without precise definition \\
The Auditing Practices Committee (APC) was formed as a subcommittee of the \\
Consultative Committee of Accountancy Bodies, (CCAB). The APC indicated support for \\
what was described as the "active" audit approach \\
"The Auditor's Consideration in Respect of Going Concern" issued as an Auditing \\
Guideline (APC, 1985). A "subject to" audit report was recommended, suggesting a \\
"passive" approach. Used the term "foreseeable future" without precise definition \\
Companies Act (1985) stipulated that financial statements should be drawn up on the \\
presumption that the company is a going concern \\
The Auditing Practices Board (APB) was formed in April, to replace the Auditing \\
Practices Committee (APC), having wider representation and more independence \\
(May) APB released the first Exposure Draft of Statement of Auditing Standard (SAS) - \\
Going Concern \\
The interim Report of the Cadbury Committee on "The Financial Aspects of Corporate \\
Governance" was issued in mid-1992, followed in December by the final report. Further \\
work was recommended to define the relative responsibilities of directors and auditors \\
with respect to identifying and reporting on going concern problems \\
(December) APB released the second Exposure Draft of Statement of Auditing Standard \\
(SAS) - Going Concern \\
The APB issued SAS 600 - Auditors' Reports on Financial Statements. The "subject to" \\
form of audit report was replaced by an unqualified report with "an explanatory paragraph" \\
APB Bulletin 1993/1 - Disclosure Relating to Corporate Governance was issued, offering \\
guidance for auditors in reporting on Cadbury Code para. 4.6 \\
ASB issued non-mandatory Operating and Financial Review (OFR) (APC, 1985). Para. 36 \\
linked to the Cadbury Code, but only in respect of proposal for disclosure by directors of \\
going concern status. The OFR was offered as location for such disclosure
\end{tabular}

APB issued SAS 130, The Going Concern Basis in Financial Statements, (APB, 1994) The Going Concern Working Group issued "Going Concern and Financial Reporting Guidance for Directors of Listed Companies Registered in the UK". Noted that financial accounting disclosures in general, and going concern disclosures in particular, are the responsibility of directors

Table I.

Chronology of

development of SAS 130 and guidance for directors on "going concern"

Table IChronology of development of SAS 130 and guidance for directors on "going concern" 
Audit firms Accountancy bodies User groups Banks Preparers Regulators Others

$\begin{array}{rrrrrrrr}\text { ED1 } & 33 & 9 & 2 & 2 & 3 & 3 & 12 \\ \text { ED2 } & 25 & 6 & 4 & 3 & 4 & 2 & 7\end{array}$

Within the above responses, the numbers commenting on both EDs were:

$\begin{array}{lllll}17 & 5 & 2 & 1 & 2\end{array}$

2

24

Table II.

Number of response letters

\section{Table IINumber of response letters}

\begin{tabular}{|c|c|c|c|c|c|c|c|}
\hline & Audit firms & Accountancy bodies & User groups & Banks & Preparers & Regulators & Others \\
\hline \multicolumn{8}{|c|}{ Generally supportive: } \\
\hline ED1 & & 5 & 2 & & 1 & & \\
\hline ED2 & 2 & 2 & & 1 & 1 & & 1 \\
\hline \multicolumn{8}{|c|}{ No specific comment (could be assumed to be supportive): } \\
\hline ED2 & 4 & 0 & 3 & 1 & 1 & 2 & 2 \\
\hline \multicolumn{8}{|c|}{ Supportive: apply procedure of a statement of adequacy of working capital. Only required when necessary. } \\
\hline ED1 & 2 & & 1 & & & & \\
\hline ED2 & 2 & & 1 & & 1 & & \\
\hline \multicolumn{8}{|c|}{ Guidance to directors should be provided: } \\
\hline ED1 & & 1 & 1 & & & 1 & \\
\hline ED2 & 2 & & & & & 1 & \\
\hline \multicolumn{8}{|c|}{ Audit standard should not seek to regulate directors: } \\
\hline ED1 & 9 & 1 & 1 & & & & \\
\hline ED2 & 3 & 1 & & & & & \\
\hline \multicolumn{8}{|c|}{ Unworkable/difficult/impracticable/misplaced: } \\
\hline ED1 & 11 & 2 & & & & & \\
\hline ED2 & 10 & 2 & & & & & \\
\hline \multicolumn{8}{|c|}{ Evidence not available from banks: } \\
\hline ED1 & 5 & & & & & & \\
\hline $\mathrm{ED} 2$ & 4 & 1 & & & & & \\
\hline \multicolumn{8}{|c|}{ The requirements should apply only to listed companies/should not apply to small companies: } \\
\hline ED1 & 22 & 4 & 1 & & & & 1 \\
\hline ED2 & 8 & 2 & & & 1 & & \\
\hline
\end{tabular}

Table IIIOpinions on written statement from directors 
Audit firms Accountancy bodies User groups Banks Preparers Regulators Others

Support for recommended period, no reason given:

$\begin{array}{llllll}\text { ED1 } & 2 & 1 & & 1 & \\ \text { ED2 } & 2 & 2 & 1 & 1 & 2\end{array}$

Support recommended period, with condition of prompter target for filing accounts:

$\begin{array}{lll}\text { ED1 } & 1 & 1 \\ \text { ED2 } & 1 & 1\end{array}$

No specific comment (could be assumed to be supportive):

$\begin{array}{lllllll}\text { ED2 } & 10 & 1 & 2 & 1 & 1 & 1\end{array}$

Preference for shorter period, no reason given:

$\begin{array}{lll}\text { ED1 } & 6 & 2\end{array}$

Impractical, unrealistic, problems beyond balance sheet date:

$\begin{array}{lllll}\text { ED1 } & 11 & 2 & 2 & 2\end{array}$

$\begin{array}{llll}\text { ED2 } & 13 & 2 & 1\end{array}$

Onerous for directors/auditors:

ED1 3

ED2 2

Obtaining a bank's confirmation of borrowing facilities may be a problem:

$\begin{array}{llcl}\text { ED1 } & 8 & 1 & 1\end{array}$

ED2 1120 Table IV.

It is important to align with the Going Concern Working Group: $\quad$ Opinions on foreseeable

$\begin{array}{llllllll}\mathrm{ED} 2 & 15 & 1 & 1 & 1 & 1 & 1 & \text { future }\end{array}$

Table IVOpinions on foreseeable future

\begin{tabular}{|c|c|c|c|c|c|c|c|c|}
\hline & Audit firms & Accountancy bodies & User groups & Banks & Preparers & Regulators & Others & \\
\hline \multicolumn{9}{|c|}{ Support additional responsibility: } \\
\hline ED1 & 8 & 3 & 1 & 1 & & 2 & 7 & \\
\hline & 3 & 1 & 2 & 1 & & & 3 & \\
\hline \multicolumn{9}{|c|}{ Support additional responsibility, subject to additional guidance to control costs: } \\
\hline \multirow{2}{*}{\multicolumn{9}{|c|}{$\begin{array}{lll}\text { ED1 } & 2 & 1 \\
\text { ED2 } & 3 & 1\end{array}$}} \\
\hline \multirow{2}{*}{\multicolumn{9}{|c|}{ No specific comment (implicit support for the proposals): }} \\
\hline & & & & & & & & \\
\hline $\mathrm{ED} 2$ & 2 & 1 & & & 1 & 2 & & \\
\hline \multicolumn{9}{|c|}{ There will be no change/current procedures are adequate: } \\
\hline \multicolumn{9}{|c|}{$\begin{array}{l}\text { There will be no change/current procedures are adequate: } \\
\text { ED1 }\end{array}$} \\
\hline \multirow{2}{*}{\multicolumn{9}{|c|}{$\begin{array}{l}\mathrm{ED2} \\
\text { Written statement from directors will extend andit work/audit will become more difficult: }\end{array}$}} \\
\hline & & & & & & & & \\
\hline \multicolumn{9}{|c|}{$\begin{array}{l}\text { Written statement from directors will extend andit work/audit will become more difficult: } \\
\text { ED1 }\end{array}$} \\
\hline \multicolumn{9}{|c|}{ ED2 $\quad 2$} \\
\hline \multicolumn{9}{|c|}{ Makes audit responsibility too open-ended and too costly: } \\
\hline ED1 & 9 & 1 & & & & 1 & & \\
\hline & 10 & 2 & & 1 & & & & \\
\hline \\
\hline \multicolumn{9}{|c|}{$\begin{array}{l}\text { Warning on extension of potential habanty of audators: } \\
\text { ED1 } \quad 1\end{array}$} \\
\hline \multirow{2}{*}{\multicolumn{9}{|c|}{$\begin{array}{l}\text { ED2 } 4 \\
\text { Warning on additional costs through switch to more active: }\end{array}$}} \\
\hline & & & & & & & & \\
\hline $\mathrm{ED} 1$ & 5 & 2 & & 1 & & & & Opinions on a more active \\
\hline ED2 & & 1 & & & 2 & & & role for auditors \\
\hline
\end{tabular}

Table VOpinions on a more active role for auditors

\section{References}

Accountancy (1992), "No obvious way out for the APB", Accountancy, No.October, pp. 25 .

Accountancy (1993), "Group outlines directors' duties", Accountancy, No.June, pp.13. 
Accountancy (1994), "Dispute over assurance period", Accountancy, No.February, pp.12.

AICPA (1981), Going Concern, Statement on Auditing Standard (SAS) No. 34, American Institute of Certified Public Accountants, New York, NY, .

APB (1992a), Draft of Proposed of Auditing Standard - Going Concern, Auditing Practices Board, London, .

APB (1992b), Draft of Proposed Auditing Standard - Auditors' Reports on Financial Statements, Auditing Practices Board, London, .

APB (1993a), Exposure Draft of Proposed of Auditing Standard - The Going

Concern Basis in Financial Statements, Auditing Practices Board, London, .

APB (1993b), SAS 600 Auditors' Reports on Financial Statements, Auditing Practices Board, London, .

APB (1994), SAS 130 The Going Concern Basis in Financial Statements, Auditing Practices Board, London, .

APB (2004), "Consultation paper: proposed international standards on auditing (UK and Ireland)", June, Auditing Practices Board, London, available at:

www.asb.org.uk/apb/, .

APC (1985), Auditing Guideline: The Auditor's Considerations in Respect of Going Concern, Auditing Practices Committee, London, .

ASB (2000), Reporting Standard FRS 18 Accounting Policies, Accounting Standards Board, London, .

ASC (1971), Statement of Standard Accounting Practice SSAP 2 Disclosure of Accounting Policies, Accounting Standards Committee, London, .

Asare, S.K. (1990), "The auditor's going concern decision: a review and implications for future research", Journal of Accounting Literature, Vol. 9 pp.39-64.

Billig, M. (1987), Arguing and Thinking: A Rhetorical Approach to Social Psychology, Cambridge University Press, Cambridge, .

Boyd, M. (1994), "Dipping into Cadbury's second layer", Accountancy, No.December, pp.95.

Cadbury (1992), The Financial Aspects of Corporate Governance - A Report of the Committee on Corporate Governance, Chaired by Sir Adrian Cadbury, Gee Publishing Ltd., London, .

Citron, D., Taffler, R. (1992), "The audit report under going concern uncertainties: an empirical analysis", Accounting and Business Research, Vol. 22 No.28, pp.337-45. 
Citron, D.B., Taffler, R.J. (1999), Audit Report Disclosures of Going Concern Uncertainties: A Continuing Puzzle, ACCA Research Report No. 60, Certified Accountants Educational Trust, London, pp.1-53.

Cockcroft, R., Cockcroft, S.M. (1992), Persuading People: An Introduction to Rhetoric, The Macmillan Press, London, .

de Saussure, F. (1974), Course in General Linguistics, Fontana, London, (originally published in 1916), .

Fairclough, N. (1995), Critical Discourse Analysis: The Critical Study of Language, Longman, London, .

GCWG (1994), Concern and Financial Reporting: Guidance for Directors of Listed Companies Registered in the UK, November, Going Concern Working Group, Institute of Chartered Accountants in England and Wales, London, .

Gold, H. (1994), "A conflict sorely in need of resolution", Accountancy, No.March, pp. 100 .

Humphrey, C., Moizer, P., Turley, S. (1993), "The audit expectations gap in Britain: an empirical investigation", Accounting and Business Research, Vol. 23 No.91A, pp.395-411.

Pong, C., Whittington, G. (1994), "The working of the Auditing Practices Committee - three case studies", Accounting and Business Research, Vol. 24 No.94, pp.157-75.

Potter, J., Wetherell, M. (1987), Discourse and Social Psychology, Sage, London, .

Sikka, P. (1992), "Audit policy making in the UK: the case of the auditor's considerations in respect of going concern", The European Accounting Review, Vol. 1 No.2, pp.349-92.

Warnock, K. (1992), "Structure and argument in accounting standards", Accounting and Business Research, Vol. 22 No.86, pp.179-88.

Wetherell, M., Taylor, S., Yates, S.J. (2001a), Discourse Theory and Practice: A Reader, Sage, London, .

Wetherell, M., Taylor, S., Yates, S.J. (2001b), Discourse as Data, Sage, London, .

Wong, P.H.Y. (2004), Challenges and Successes in Implementing International Standards: Achieving Convergence to IFRSs and ISAs, International Federation of Accountants, New York, NY, .

\section{Further Reading}

APB (2004), Going Concern, International Standard on Auditing (UK and Ireland) 570, December, Auditing Practices Board, London, available at:

www.asb.org.uk/apb/, . 
Walton, P. (1991), The True and Fair View: A Shifting Concept, Association of Chartered Certified Accountants, London, Occasional Research Paper No. 7, Vol. 7.

Walton, P. (1993), "Introduction: the true and fair view in British accounting", European Accounting Review, Vol. 1 pp.49-58.

\section{Appendix}

This appendix summarises the rhetorical devices observed in the exposure drafts and standard, extracted from the list of rhetorical devices described in Cockcroft and Cockcroft (1992, pp. 158-161).

\section{From Aristotle:}

- Ethos persuasion through personality and stance.

- Pathos persuasion through the arousal of emotion.

- Logos persuasion through reasoning.

\section{Persuasive repertoire (as classified by Cockcroft and Cockcroft)}

\section{Lexical choice}

The vocabulary used in a document has persuasive power. Also, the words chosen may indicate the stance taken by the writer.

\section{Sound patterning}

Sound patterns such as alliteration or onomatopoeia create and enhance meaning.

\section{Trope or figurative language}

To turn meanings in words via a less direct form of association: Metonymy (substitution of one word for another with which it is associated), e.g. substituting a people-involving entity for the people involved, or container/content.

\section{Schematic language}

Word play, syntactic devices, amplification and diminution, tricks and ploys.

1. Antithesis: (choice or arrangement of words to emphasise a contrast).

2. Syntactic devices:

- Verb-based variation (differing permutations of the subject/ verb/ object structure).

- Syntactic parallelism (a similar rhythm within the paragraph as a whole).

- Conjunction (use of linking words such as "therefore" or "thus" to create an appearance of logical flow).

3. Amplification and diminution:

- Leading summary (a brief summary statement is followed by detailed amplification). 
4. Tricks and ploys:

- Open question (a question to which we don't know the answer).

- Question and answer (asking, and responding to, a series of questions devised by the writer);

- Referring (showing confidence by referring a matter- as self-evident to the judgment of the audience); and

- Making it clear (a claim to have "made it clear" implies that a previous question has now been answered).

\section{Corresponding author}

Pauline Weetman can be contacted at: p.weetman@strath.ac.uk 